\title{
Shutter Device
}

National Cancer Institute

\section{Source}

National Cancer Institute. Shutter Device. NCI Thesaurus. Code C50175.

A mechanical or electronic device designed to regulate an exposure time, especially the one in a camera. 